\title{
Effect of Meteorological Factors on Composition of Aerial Biomass in a Dairy Plant
}

\author{
Usha Kumari $^{1}$ and Raj Kishor Sharma ${ }^{2 *}$ \\ ${ }^{1}$ Department of Botany, P.M.J. College, V.K.S.U. Ara, India \\ ${ }^{2}$ Dept. of Microbiology, IGIMS, Patna, India
}

\section{A B S T R A C T}

\section{Keywords \\ Ara, Aerial biomass, Health of people, \\ Meteorological factors}

Article Info

Accepted:

10 November 2018

Available Online:

10 December 2018
Aerial biomass forms an essential ingredient of air. Air is one of the most essential requirements for the survival of mankind and other animals on this planet. The quality and composition of air change with the change in aerial biomass. Meteorological factors viz. temperature (T), relative humidity $(\mathrm{RH})$ and rainfall (RF) affect the composition of air. Meteorological factors affect the health of people by changing the composition of air we breathe. A study was done to assess the impact of meteorological factors on aerial biomass and hence on health of the people. The present study clearly showed the variation in pattern of health problems with variation in meteorological factors establishing the relationship between meteorological factors and health of the people.

\section{Introduction}

Aerial biomass refers to the biological materials present in the air. Biological materials include Viruses, Bacteria, Fungal spora, Pollen grains, Trichomes, Enterobacteria, Protozoan cysts, Spores of algae-moss-ferns, minute insects and seeds, etc. They are also known as Airborne bioparticulates. Airborne bioparticulates are transported by turbulent air. Aerial biomass varies from one geographical area to another. Apart from seasonal variation, it also varies at different hours of the day. Aerobiology refers to the study of aerospora and particulates of biological origin and their various processes viz. source of their release, dissemination, passive transport, deposition and effect on the health-hazard of other biotic communities on the earth's surface. Airborne Bioparticulates are found from $0.2 \mathrm{~mm}$ to $20 \mathrm{kms}$ of height in air. Aerobiology also deals with the effects of pollutant gases (e.g. $\mathrm{SO}_{2}, \mathrm{CO}_{2}$, Freon, $\mathrm{H}_{2} \mathrm{~S}$, ozone, etc.) and meteorological factors (like $\mathrm{T}$, $\mathrm{RH}, \mathrm{RF}$ ), on the viability of microbes and other biological materials.

Over the last few decades, there has been a change in baseline temperature (global warming) and meteorological patterns of rainfall, wind velocity and relative humidity. These changes have been brought out due to 
various human activities like industrialization, massive use of automobiles as means of transport, unplanned urbanization, massive destruction of vegetations, construction of buildings, roads, dams and other engineering works etc. People have been observing the effects of meteorological factors on mankind, animals and crops and vice-versa since time immemorial. Tilak (1989) and Alturi et al., (1990) reported that aeromicrobial forms are well known for causing diseases of allergic and infectious categories in human beings. The history is replete with several examples where people used to predict the likely environmental changes in forthcoming days by observing the changes in behaviour of several insects and animals. Direction of wind flow helps in transport of an infectious microorganism from one geographical area to another. Moisture content of the air affect the breeding and survival of infective microorganism \& their pathogenic cystic forms. Sudarshanam et al., (2011) on his study on aeromicrobial load in hospital in Chennai also reported that aerospora are affected by temperature \& relative humidity. People have used the velocity and direction of wind flow to defeat enemy by infiltrating the air with pathogenic microorganisms like Variola causing small pox \& Bacillus anthracis causing Anthrax, this practice being referred to as Biological warfare. In coming years this mode of warfare is going to gain vital importance by virtue of its silent nature, low cost and massive destruction of the fighting forces.

\section{Materials and Methods}

Study was conducted at Ara town in Bihar during June 2009 to May 2011. Ara is the head quarter of district Bhojpur of Bihar state. Ara is famous for being the birthplace of Babu Veer Kunwar Singh, one of the pioneer freedom fighters of India's first freedom movement of 1857 against British Rule. Meteorological factors included in the study were Temperature (T), Rainfall and Relative humidity (RH). All meteorological data were obtained from Krishi Vigyan Kendra, SCADA, Japani farm, Ara. The study was conducted in the following manner-

1. Periodical isolation of aeromicrobes on $10^{\text {th }}$ $\& 25^{\text {th }}$ of each month from selected experimental site at $1.5 \mathrm{~m}$ height with rotorod air sampler followed by exposing petriplates containing MacConkey medium through gravitational sampling technique at 8:30 and 17:30/18:30 hours inside Sudha dairy plant, Ara.

2. Arms of rotorod adhered with glycerine jelly coated cello tapes were exposed for 10 min at each diurnal hour. The exposed cellotapes were displaced from rotorod air sampler arms with the help of forceps and placed on a slide centrally with its sticky surface downward and jelly coated ones upwardly parallel to each other at a distance of 2-3mm. cellotapes were covered using cover slips $(50 \mathrm{~mm} \times 22 \mathrm{~mm})$ and prepared slide was sealed using quickfix for further microscopic examination after proper labeling.

3. Possible clinical tests of injurious microbes causing allergic and pathogenic diseases in workers and people living in the vicinity of plants with the help of locally available physicians of modern medicine.

4. Analysis of meteorological data in association with microbial load on diurnal and seasonal basis.

5. Survey of health of the people public

6. Statistical analysis of the obtained data.

The rotorod air sampler used during study has been fabricated, designed and improved by Sinha, Mishra and Singh (1990). 


\section{Results and Discussion}

Aeromicrobial load was calculated by number of various microbes trapped per $/ \mathrm{m}^{3}$ of air sampled. Seasonal and diurnal variations of total fungal spora \& other miscellaneous types of biota expressed as per metre $\left(\mathrm{m}^{3}\right)$ of sampled air were noted during the study. All the airborne bioparticulates trapped during study were broadly classified in to two groups.

Group 1 comprising Zygomycotina, Ascomycotina, Basidiomycotina \& Dueteromycotina

Group 2 comprised of Protozoa (cysts \& E. coli), pollen grains, insect scales and unidentified plant trichomes

Aeroallergic microbes and spores isolated during the period of investigation (June 2009 - May 2011) were- Chaetomium, Alternaria, Aspergillus, Cladosporium, Drechslera, Mucor,Penicillium, Rhizopus, Memnoniella, Nigrospora, Leptosphaeria, Syncephalastrum, Fusarium, Epicoccum; with Chaetomium contributing the most (13.8 percent). From the above tables, it is very clear that a significant difference in microbial load occurs at the two different times of collection. The microbial load was more in the evening compared to morning hour of collection. Seasonally, the highest microbial load was recorded during rainy season followed by winter $\&$ summer

A preliminary survey of the people around the Krishi Vigyan Kendra, Ara and Sudha dairy plant revealed that about 8-10 percent people were having allergic disease like asthma, chronic urticaria, eczema, cough \& cold and other infectious diseases like gastroenteritis, conjunctivitis, urinary tract infections. It was observed that the incidence of diseases was the highest (51 percent) during rainy season followed by winter (32 percent) and summer season (17 percent). The variation in pattern of diseases clearly shows relationship with the changes in meteorological factors evident by different seasons. Rainy season with the highest microbial load reported with the highest incidence of the diseases (Table 1 and 2).

Table.1 Seasonal variations of fungal microbes $/ \mathrm{m}^{3}$ of the sampled air

\begin{tabular}{|l|l|l|l|l|l|}
\hline & Summer & & Rainy & & Winter \\
\hline March & 1155 & July & 2898 & Nov. & 1878 \\
\hline April & 1098 & August & 3288 & Dec. & 1443 \\
\hline May & 855 & Sept. & 3282 & Jan. & 987 \\
\hline June & 2060 & October & 2616 & Feb. & 1056 \\
\hline & & & & & \\
\hline
\end{tabular}

Table.2 Diurnal variations of microbes $/ \mathrm{m}^{3}$ of the sampled air collected

\begin{tabular}{|l|l|l|}
\hline Diurnal hour & Summer & Rainy \\
\hline $\mathbf{0 8 : 3 0}$ hrs & 3078 & 6592 \\
\hline $\mathbf{1 7 : 3 0}$ hrs & 3231 & 6731 \\
\hline
\end{tabular}


Figure.1 Various genara of fungi isolated

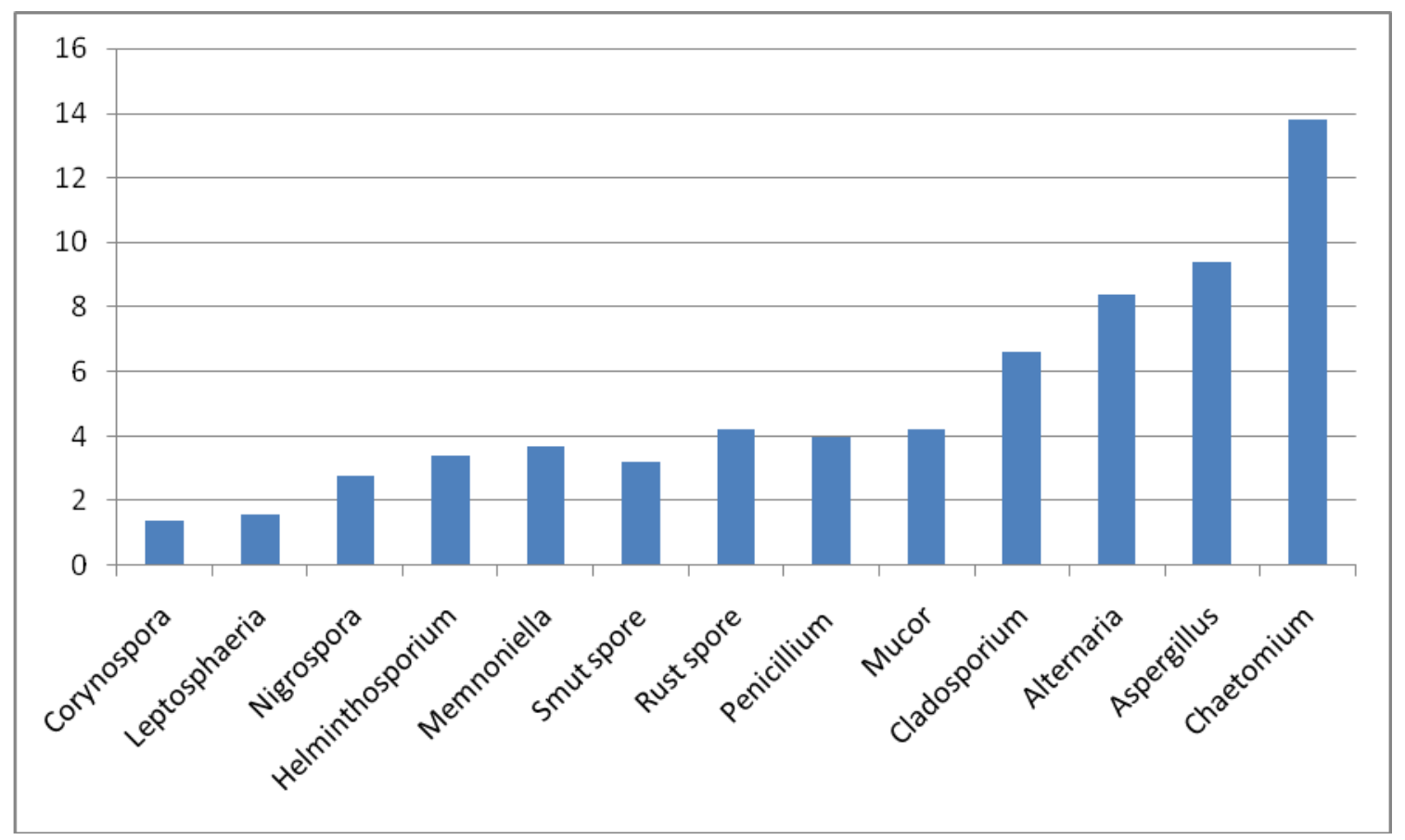

Aerobiology plays an important role in the welfare of mankind and other biotic communities of the ecosystem. Aeromicrobial forms are well known for causing diseases of allergic and infectious categories in human beings. In this age of continuously changing climate throughout the world, the role of aerobiologists is going to be very crucial. The study of effect of environmental factors on health and crops have attracted aerobiologists, environmentalists, agriculture scientists and doctors throughout the world. This study was done with an aim to assess the impact of meteorological factors on aerial biomass and hence the health of human beings. The present study shows that the composition of aerial biomass is affected by temperature, rainfall and relative humidity. The change in aerial biomass was associated with changes in the pattern of diseases affecting human lives and hence proving that the health is affected by meteorological factors. Present study is in conformity with several earlier studies done in different parts of the world. Gregory (1961) reported the diurnal variations in aerobacteria.
Chandra and Singh (1994) also reported the highest load of airborne bacteria during rainy season. Chauhan, Kulshreshtha et al., (2004) in their study on allergenic significance of airborne fungi in Agra also reported similar findings. Cholke and Mahajan (2008) studied aeromicroflora inside poultry shed in Pune and reported the effect of season and meteorological factors on aerospora and health of workers.

It is concluded that the present piece of research clearly indicates the importance of aerobiology on health of the society. Continuous monitoring of changes in meteorological factors is required for the betterment of human life. Strict regulatory measures are the need of hour to address the rapidly changing environmental factors and hence preventing people from several diseases. This study may work as a guiding tool for physicians to correlate the symptoms prevalent in this town. It can be used by local municipal corporation in controlling the harmful practices leading to change in 
environmental. Municipal authority and other responsible government body may take corrective steps at the beginning of deteriorating environmental factors and likelihood of related illnesses in the society. A sincere effort is needed for increasing the awareness of public regarding the importance of interrelationship between meteorological factors and their health. Increased awareness will lead to expected decrease in behavior of the people causing deterioration in environmental factors.

\section{References}

Alturi JB, Appana N. 1990. A survey of airborne allergenic fungal spores at Vijaywada. Journal of Env. Bio. 11(3): 321-29.

Chandra N, Singh I. Incidence of airborne bacteria in silkworms rearing rooms and their pathogenicity. Frontier Botanist 1994; 125-133.

Chauhan SVS, Kulshrestha A, and Goal R. Airborne fungi of Agra city with special reference to their allergenic significance. Ind. J. of Aerobiology 2004; 17: 17-24.

Cholke PB and Mahajan MC. Study of aeromycoflora inside poultry shed.
Ind. J. of Aerobiology 2008; 21: 7378.

Gregory PH. Microbiology of the Atmosphere. $2^{\text {nd }}$ edit. Leonard Hill, Intern Text Books Co. Ltd., Aylesburg, Bucks, U.K.1973: 112114.

Lacey J. Aerobiology and Health-the role of airborne fungal spores in respiratory diseases. Frontiers in Mycology Ed. Ho nks worth, CAB Intern, Kew, U.k.

Sinha SS. Aerobiology and its relevance in treatment of allergic diseases. Abstracts. $30^{\text {th }}$ Ann. Conv. of Indian college of Allergy and Applied Immunology.1996; B.J. Medical College, Ahmedabad.

Sinha SS. Fundamentals of Aerobiology. 2013. Research Periodicals \& Books Publ. House, Housten, USA.

Sudarshanam S, Annamalai R et al., 2011. Factors affecting the microbial loads in indoor bioaerosols of a closed system in a health care facility in tropical settings. Ind. J. of Aerobiology, 24: 7-11.

Tilak S T and Jogdand S B. 1989. Clinical investigation of allergens. Atmos. Biopol. Ed. N. Chandra. Pp. 143-51.

\section{How to cite this article:}

Usha Kumari and Raj Kishor Sharma. 2018. Effect of Meteorological Factors on Composition of Aerial Biomass in a Dairy Plant. Int.J.Curr.Microbiol.App.Sci. 7(12): 994-998.

doi: https://doi.org/10.20546/ijcmas.2018.712.123 